\title{
On the many accounts of public happiness
}

\author{
Alois Stutzer • Tommaso Reggiani
}

Published online: 23 April 2014

(C) Springer-Verlag Berlin Heidelberg 2014

\begin{abstract}
Economists of the HEIRS association for Happiness Economics and Interpersonal Relations promote a better understanding of the fundamental importance of sociality for people's happiness. The 2013 conference on "Public Happiness" did justice to this goal and provided an overview of stimulating new developments in the study of people's well-being. The special issue focuses on the one hand on social comparison processes that most naturally emerge if people form interpersonal connections. On the other hand, it contributes to the conceptualization of the many different accounts of public happiness.
\end{abstract}

\section{On the many accounts of public happiness}

The eighteenth-century Italian scholarship on "pubblica felicità"1 emphasizes a deep link between happiness and sociality that hardly anybody would want to negate but still many neglect in current research on human well-being. The HEIRS

\footnotetext{
1 An accounting of the ideas in the context of modern economics is provided, for example, in Bruni (2006) and Bruni and Zamagni (2007).
}

\footnotetext{
A. Stutzer

Faculty of Business and Economics, University of Basel, Peter Merian-Weg 6, 4002 Basel, Switzerland

e-mail: alois.stutzer@unibas.ch

T. Reggiani $(\bowtie)$

Faculty of Management, Economics and Social Sciences (Chair: Corporate Development and Business Ethics), University of Cologne, Albertus-Magnus-Platz, 50923 Cologne, Germany e-mail: tommaso.reggiani@uni-koeln.de
} 
association for Happiness Economics and Interpersonal Relations ${ }^{2}$ advances the idea of public happiness that strongly relies on high-quality interpersonal relationships and supports its systematic scientific study through conferences. The 2013 conference on "Public Happiness" 3 provided an insight into the current stimulating developments in this area of thought and research. ${ }^{4}$

A key insight from the conference, in our mind, was that following up many different accounts of public happiness might well serve best when people want input on how to pursue both individually and collectively their ideas of the good life. Simultaneously, it does help to critically reflect and better understand the various accounts of (public) happiness that are applied. There are not only different theoretical conceptualizations and philosophical accounts of public happiness but also alternative empirical approaches to capture how people judge and experience their life.

We first briefly lay out some aspects of public happiness. Second, we list some of the takes on the issue that were pursued at the conference. Third, the contributions in this special issue are briefly introduced.

\section{Some perspectives on public happiness}

Accounts of public happiness emerge when we try to understand the determinants of high individual happiness. In fact, the largest part of the literature in the new empirical economics of happiness studies the covariates of high reported individual well-being that go beyond individual personal characteristics. These aspects involve the (macro) economic situation in terms of income (security), the state of the labor market, inflation or income inequality. However, they also involve the many institutions people set up to organize their cohabitation, most importantly democratic rules to organize collective decision-making on public issues. ${ }^{5}$

A different angle of public happiness is emphasized if individual well-being is understood as the result of other people's actions. Most of these effects are channeled anonymously through market interaction. However, many interactions are also personal. In fact, many scholars of the HEIRS network provided important insights to put the economic determinants of happiness into perspective by studying alternative sources of well-being. It turns out that happiness depends much on personal relationships, i.e., the quantity and quality of social relations that people have with family, friends, work mates and fellow community members. If these relationships, often referred to as social capital, are good, people experience high

\footnotetext{
${ }^{2}$ http://www.heirs.it.

${ }^{3}$ The "Public Happiness-HEIRS conference 2013" took place in Rome 4-5 June 2013 benefiting from the hospitality of the Pontifical University of St. Thomas Aquinas, Rome (co-organizers: LUMSA University, University of Milan-Bicocca \& CISEPS, University of Rome-Tor Vergata).

${ }^{4}$ Two earlier Special Issues of IREC capture the evolution of this debate. The issues introduced by Gui and Stanca (2010, Vol. 57(2)) and Bruni (2012, Vol. 59(4)) provide an interesting interdisciplinary overview of this research domain.

${ }^{5}$ Reviews of the empirical literature on the determinants of reported subjective well-being are provided, e.g., in Dolan et al. (2008), Stutzer and Frey (2010) or the papers collected in Frey and Stutzer (2013).
} 
subjective well-being (for a review, see Helliwell and Putnam 2004; Powdthavee 2008). Importantly, the benefits of social capital are not confined to outcomes like informal mutual assistance or the access to valuable information due to weak ties. There is rather a strong non-instrumental component of interpersonal relationships that contributes to individual well-being. These so called relational goods involve socializing as an important aspect (see the contributions in Bruni and Porta 2007). They also have a public good component as one persons' engagement in social relations makes them more rewarding for others (Becchetti et al. 2008). In addition to socializing, there is also empirical evidence that performing volunteer work is rewarding in itself (e.g., Meier and Stutzer 2008).

Given the importance of social relations for human well-being, changes in their quality have been argued to drive long-term trends in people's reported subjective well-being (Bartolini 2012; Sarracino 2010). To what extent the development of happiness over time has to be understood as an interaction between economic factors and aspects of social capital is so far an open issue. While the literature on relative income emphasizes income comparisons as a source of dissatisfaction or negative externalities (Clark and Senik 2010; Card et al. 2012), interpersonal relationships are not seen as positional and rather to be beneficial also for others (i.e., involving activities with positive externalities). Both lines of reasoning might well benefit from each other as personal relationships facilitate social support favoring people with a relatively lower economic standing. Moreover, social comparisons are facilitated along many more dimensions if interpersonal relations are maintained and so potentially affect well-being. The latter aspect gives rise to an account of public happiness emphasizing that well-being is by nature built on interdependent utility. Many emotions are experienced in response to human interaction.

\section{A flashback to the conference}

The conference saw a vivid exchange around the presentations of more than eighty papers in parallel and plenary sessions. Robert Sugden most clearly established a connection between the original thoughts on public happiness and modern research in his presentation entitled "Being useful to one another in a market economy." Likewise, perfected Stefano Zamagni the central theme of the conference in his concluding remarks (included in this special issue). Carol Ryff in her presentation "Evaluating targets for improving society: Public happiness versus public purpose" and Ruut Veenhoven with his talk on "Greater happiness for a greater number: Did the promise of enlightenment come true?" both provided convincing conceptual perspectives on how to study public happiness and, importantly, how to link theoretical accounts and empirical concepts. Emphasizing the role of social comparisons for individual well-being, Bruno Frey highlighted the many open issues in our understanding of interdependent happiness (see the paper in this issue). Alois Stutzer exemplified the study of public happiness based on an application to tobacco control policies presenting evidence for the effects of smoking bans and cigarette taxes on the life satisfaction of people in Europe. 


\section{The special issue}

The papers published in this special issue draw a wide bow over the topic of public happiness including an almost exclusive empirical contribution but also theoretical considerations with philosophical foundations. The first paper by Bruno et al. (2014) takes up an important aspect of concepts of interdependent utility, i.e., the question of who is included in the reference group. A series of ideas are discussed on how to extend the often mechanically chosen range of possible comparison standards. The paper provides stimulating thoughts on how to proceed conceptually. Implicitly, the paper also asks for alternative ways to approach reference group effects empirically. Devrim (2014) in the second paper provides an empirical account simultaneously including various measures of relative income to get an idea what comparisons might matter empirically. He compares relative income effect in transition economies to relative income effects in developed industrial economies. The findings might well help to further develop hypotheses on the role of relative income in individual happiness. The last two papers address the notion of individualism in relation to happiness and well-being concerns. From a political philosophy perspective, Robert (2014) proposes the concept of "plural individuality" where individuals are relationally constituted. According to his analysis, this approach offers a more adequate account of the individual in which the political plays a significant role. The approach is especially addressing the pursuit of happiness in the public domain. Adopting more a view toward economics, Mozaffar (2014) in the last paper argues about the groundlessness of the suspicion that modern accounts of well-being in the utilitarian tradition, that has strongly shaped welfare economics, entail excessively individualistic views in the domain of happiness studies.

We very much hope that the conference has inspired fruitful research efforts so that there will be further Special Issues of IREC on happiness and economics in the future.

\section{References}

Bartolini S (2012) Sociability predicts happiness in nations: evidence from macro and micro data. In: Bartolini S (ed) Policies for happiness. Oxford University Press, Oxford

Becchetti L, Pelloni A, Rossetti F (2008) Relational goods, sociability, and happiness. Kyklos 61(3):343-363

Bruni L (2006) Civil happiness. Economics and human flourishing in historical perspective. Routledge, Abingdon

Bruni L (2012) Introduction: special issue "market and happiness". Int Rev Econ 59(4):321-333

Bruni L, Porta PL (eds) (2007) Handbook on the economics of happiness. Edward Elgar, Cheltenham

Bruni L, Zamagni S (2007) Civil economy. Peter Lang, Oxford

Bruno SF, Gallus J, Steiner L (2014) Open issues in happiness research. Int Rev Econ. doi:10.1007/ s12232-014-0203-y (this issue)

Card D, Mas A, Moretti E, Saez E (2012) Inequality at work: the effect of peer salaries on job satisfaction. Am Econ Rev 102(6):2981-3003

Clark A, Senik C (2010) Who compares to whom? The anatomy of income comparisons in Europe. Econ J 120(544):573-594

Devrim D (2014) Satisfaction and comparison income in transition and developed economies. Int Rev Econ. doi:10.1007/s12232-014-0201-0 (this issue) 
Dolan P, Peasgood T, White M (2008) Do we really know what makes us happy? A review of the economic literature on the factors associated with subjective well-being. J Econ Psychol 29(1):94-122

Frey BS, Stutzer A (eds) (2013) Recent developments in the economics of happiness. The international library of critical writings in economics series. Edward Elgar, Cheltenham

Gui B, Stanca L (2010) Happiness and relational goods: well-being and interpersonal relations in the economic sphere. Int Rev Econ 57(2):105-118

Helliwell J, Putnam RD (2004) The social context of well-being. Philos Trans R Soc Lond Ser B Biol Sci 359(1449):1435-1446

Meier S, Stutzer A (2008) Is volunteering rewarding in itself? Economica 75(297):39-59

Mozaffar Q (2014) Are modern philosophical accounts of well-being excessively 'individualistic'? Int Rev Econ. doi:10.1007/s12232-014-0204-x (this issue)

Powdthavee N (2008) Putting a price tag on friends, relatives, and neighbours: using surveys of life satisfaction to value social relationships. J Soc Econ 37(4):1459-1480

Robert U (2014) The significance of the political: individuality and public happiness. Int Rev Econ. doi:10.1007/s12232-014-0202-z (this issue)

Sarracino F (2010) Social capital and subjective well-being trends: comparing 11 Western European countries. J Soc Econ 39(4):482-517

Stutzer A, Frey BS (2010) Recent advances in the economics of individual subjective well-Being. Soc Res Int Q 77(2):679-714 